\title{
Sexual Dimorphism in Pelvic Bone Shape of the North Pacific Common Minke Whales (Ballaenoptera acutorostrata)
}

\author{
Naoko Miyakawa $^{1 *}$, Toshiya Kishiro², Yoshihiro Fujise ${ }^{3}$, Gen Nakamura1, Hidehiro Kato ${ }^{1}$ \\ ${ }^{1}$ Laboratory of Cetacean Biology, Tokyo University of Marine Science and Technology, Tokyo, Japan \\ ${ }^{2}$ National Research Institute of Far Seas Fisheries, Yokohama, Japan \\ ${ }^{3}$ Institute of Cetacean Research, Tokyo, Japan \\ Email: *n_m19880108@yahoo.co.jp
}

Received 16 February 2016; accepted 18 April 2016; published 21 April 2016

Copyright (C) 2016 by authors and Scientific Research Publishing Inc.

This work is licensed under the Creative Commons Attribution International License (CC BY). http://creativecommons.org/licenses/by/4.0/

\section{(c) (i) Open Access}

\begin{abstract}
Little is known about the morphology of the pelvic girdle of modern cetaceans, although many species have a vestigial pelvis (pelvic bone) and part of the hind limb bones inside the body. Previous studies have focused almost exclusively on hard tissues as well, despite the fact that the bones are comprised of cartilaginous tissue, especially in the case of femur. In the present study, we characterized the pelvic bones and searched for vestigial femurs among 43 North Pacific common minke whales (Balaenoptera acutorostrata), all of which were sexually mature individuals. The shape of the pelvic bones clearly differs depending on sex. Specifically, the pelvic bones of females were flat, but those of adult males consist of two types: one with a twisted caudal portion (Twisted type) and the other with a thickened caudal portion (Hypertrophied type). Those pelvic bone features in male are found only among North Pacific common minke whales. $98 \%$ of the individuals in this study had vestigial femur. The presence rate of vestigial femur may differ by subspecies. The shape of the pelvic and hind limb bones of modern cetaceans may vary between species and probably by region, at least at the Ocean basin scale.
\end{abstract}

\section{Keywords}

Pelvic Bone, Femur, Cartilage, Common Minke Whale, Sexual Dimorphism

\section{Introduction}

Modern cetaceans evolved from terrestrial quadrupedal mammals through evolutionary processes that involved

${ }^{*}$ Corresponding author.

How to cite this paper: Miyakawa, N., Kishiro, T., Fujise, Y., Nakamura, G. and Kato, H. (2016) Sexual Dimorphism in Pelvic Bone Shape of the North Pacific Common Minke Whales (Balaenoptera acutorostrata). Open Journal of Animal Sciences, 6, 131-136. http://dx.doi.org/10.4236/ojas.2016.62016 
the pelvis forming a simple triangular or rod-shaped bone and degeneration of the hind limb into small bones which were typically not visible from the body surface. The vestigial pelvis of modern cetaceans is termed pelvic bone.

The pelvic bones of modern cetaceans are generally triangular in shape in mysticetes and elongated stick-like structures in odontocetes, and are disarticulated from the vertebral column and embedded in the muscular layer [1]-[5]. Several previous studies have reported that the pelvic bones display sexual variation in morphology. For example, the lateral process of the female pelvic bone is located more caudally than that of males for Bryde's, fin and blue whales among mysticetes, and the male pelvic bone tends to be larger than in females for odontocetes [3] [5]-[11]. In addition to sexual variation, the shape of the pelvic bone of modern cetaceans also differs between species [3] [12]. To date, however, few studies have examined the morphological characteristics of the pelvic bone in each species.

The pelvic bone of modern cetaceans is composed entirely of cartilage at birth and gradually ossifies with growth [1]-[3] [13]. In pelvic bone specimens treated by boiling in previous studies, most of the cartilage was lost from the pelvic girdle. Thus, the exact shape of the entire pelvic bone remains unclear.

For vestigial hind limbs, differences by species are observed. Hosokawa (1951) [3] recognized three groups of baleen whales based on the degree of retention of the vestigial hind limbs: 1) bowhead whales (Balaena mysticetus) which retain the femur and tibia; 2) fin whales (Balaenoptera physalus), blue whales (Balaenoptera musculus) and humpback whales (Megaptera novaeangliae), with only the femur remaining; and 3) sei whales (Balaenoptera borealis) and common minke whales (Balaenoptera acutorostrata), which retain none. However, Heyerdahl (1973) [1] later reported that certain Atlantic individuals of the common minke whale had a vestigial femur. Therefore, the information of vestigial hind limb is ambiguous.

In addition, it is difficult to study baleen whales due to the large size of the body. In this study, we attempted to clarify sexual differences with respect to cartilage of common minke whales from the North Pacific.

\section{Materials and Methods}

\subsection{Materials}

We examined pelvic bones and vestigial hind limbs with cartilage, which are registered sample sets in possession of TUMSAT Museum of Marine Science, Tokyo University of Marine Science and Technology. Those involved 43 sexually mature common minke whales (15 females, mean body length: $8.0 \mathrm{~m}$; 28 males, mean body length: $7.3 \mathrm{~m}$ ) were sexually mature, originally taken from the Japanese Whale Research Program under the IWC Special Permit, in waters off Pacific coast of northern Japan (Sendai Bay, $38^{\circ}-17.5 \mathrm{~N}, 141^{\circ}-30.2 \mathrm{E}$; neritic waters off Kushiro, $\left.42^{\circ}-58.5 \mathrm{~N}, 144^{\circ}-21.5 \mathrm{E}\right)$ during the period of $2009-2013$.

\subsection{Methods}

The pelvic bones and hind limbs were removed with a knife from the ventral side of the body together with their surrounding tissues. The pelvic bones and vestigial hind limb bones with cartilage were separated from the surrounding tissues using a scalpel and tweezers. The samples were fixed in $10 \%$ neutral buffered formalin followed by $70 \%$ ethanol.

The maximum thickness and distances between 3 points (features 1 - 3) on the left pelvic bones were measured with Vernier calipers to the nearest $1 \mathrm{~mm}$ (Figure 1). An indicator of the position of the lateral process was calculated by dividing the measured value for feature 3 divided by that for feature 1 . We looked at measured values as well as relative values of width and maximum thickness against pelvic bone length and pelvic bone length against body length. Sexual difference in measured values was tested by t-test, and relative values by Mann-Whitney U-test.

Data for body length, sex and determination of sexual maturity of each whale were acquired from The Institute of Cetacean Research and National Research Institute of Far Seas Fisheries, Fisheries Research Agency, Japan.

\section{Results}

\subsection{Pelvic Bone}

Pelvic bones of the common minke whales examined were elongated in the cranial direction and triangular in 


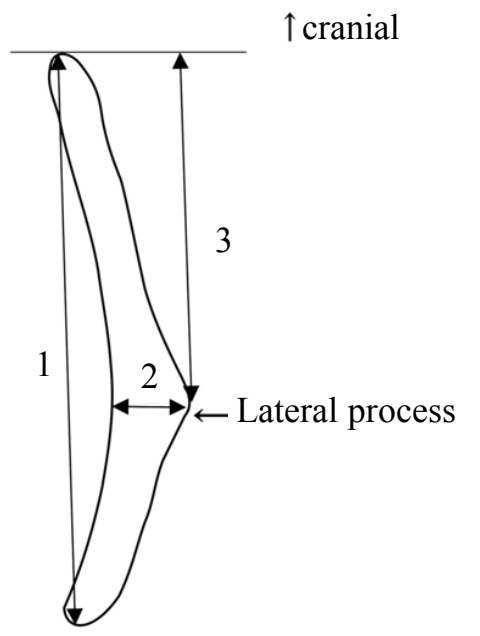

Figure 1. Measurement points for left pelvic bones viewed from the ventral side. 1, length; 2, width; and 3, distance between lateral process and cranial end of the bone.

the caudal direction. The bones also had a process protruding from the intermediate part on the lateral side and curved inward, which are common features among Balaenopterid species (Figure 2). Additionally, the dorsal surface appears flat, whereas the ventral surface was circular (Figure 3).

Pelvic bones of common minke whales differed by sex (Figure 3 ). In all females, the pelvic bones were relatively flat. On the other hand, two distinct morphological types of pelvic bones were observed in males. In the first type, which we call "Twisted type", the caudal portion of the pelvic bone was twisted so that the lateral process actually faces the dorsal side $(n=12)$. In the second type, which we called "Hypertrophied type", the caudal portion was not twisted and had an increased interior thickness $(n=14)$. The bone portion with maximum thickness was located at the lateral process in females, but at the caudal region in males. The pelvic bone of males was thicker than that of females in both measured values and relative values (Table 1, Table 2). In addition, sexual difference was detected in the position of the lateral process. The mean value of the position indicator in females were higher than in males, indicating that the lateral process of the pelvic bone was located more caudally in females than in males (Table 2).

No sexual difference was detected in relative values of length (Table 2). However, the pelvic bones of females were significantly longer than that of males in terms of measured value (Table 1). The body length of females was larger than that of males. So, although the sexual difference was detected in measured value of pelvic bone length, the proportion of pelvic bone to body length was not different in either sex. This apparent mismatch was also the case for pelvic bone width, with sexual difference detected measured value but not in relative value. Sexual difference was detected in the measured value of pelvic bone width and that was not detected in the relative value to pelvic bone length, because the pelvic bone length and width in the measured values of females were larger than that of male.

\subsection{Vestigial Hind Limbs}

In contrast to the findings of Hosokawa (1951) [3], who reported that common minke whales had no vestigial hind limb bones, $98 \%$ of the common minke whales sampled in the present study had vestigial femurs (42/43 specimens). Sexual difference was not observed in the presence rate of vestigial femur. The vestigial femur was a ball-like bone attached to the ventral face of the pelvic bone by the fibra and muscles (Figure 2). However, in a small number of individuals (2/43 specimens), the vestigial femur was fused with the pelvic bone.

\section{Discussion}

The present study and past studies suggest that pelvic bones of cetaceans have similar morphologic features. The males of certain species of cetaceans have relatively thick pelvic bones compared to females [5]-[11] [14]. In Bryde's, blue and fin whales, the lateral process of the pelvic bone is reportedly located more caudally in females than in males [3] [5], as was found here in the North Pacific common minke whale. 
(a)

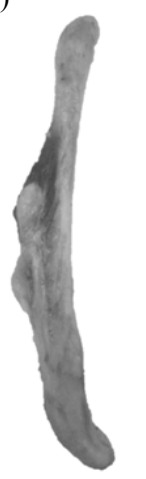

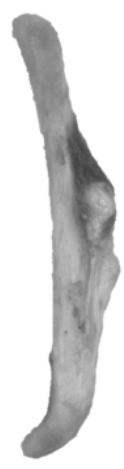

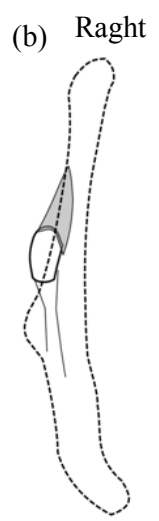

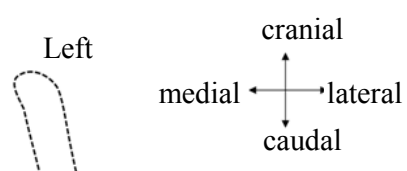

caudal

Figure 2. Photograph and pattern diagram of the pelvic bone and vestigial femur viewed from the ventral side. (a) Photograph and (b) pattern diagram. The dashed lines indicate the pelvic bone, and the solid line outlines the vestigial femur in pattern diagram. The gray area in pattern diagram described muscle, which connect pelvic bone and vestigial femur.

(a)

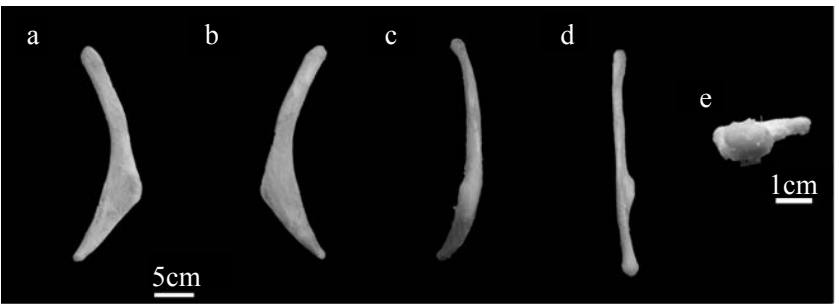

(b)

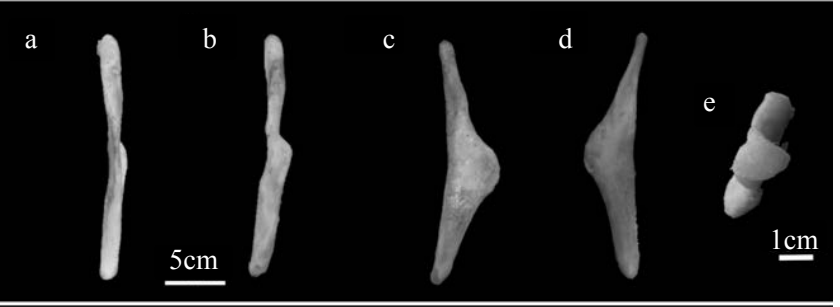

(c)

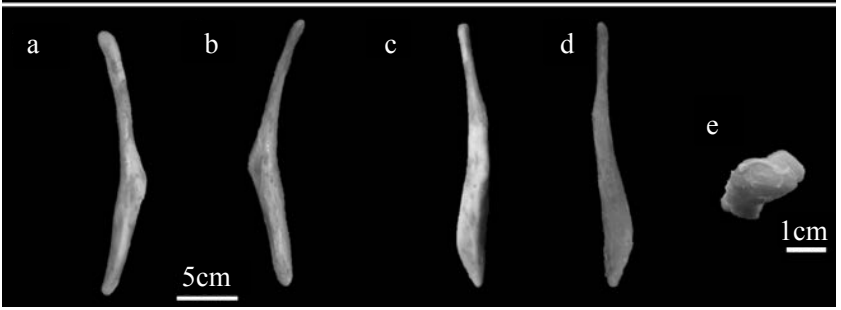

Figure 3. Photograph showing the differences in the left pelvic bone shape based on sex. (a) Female; (b) male (Twisted type); and (c) male (Hypertrophied Type). a, ventral view; b, dorsal view; c, lateral view; $d$, medial view; and e, cranial view. The angle of the caudal region of the pelvic bone was found to differ.

Table 1. Sexual difference in the measured values.

\begin{tabular}{cccccc}
\hline & \multicolumn{2}{c}{ Female } & \multicolumn{2}{c}{ Male } & Sexual difference \\
\cline { 2 - 6 } & $n$ & Mean \pm SD & $n$ & Mean \pm SD & $\mathrm{P}<0.05$ \\
\hline Pelvic bone length $(\mathrm{cm})$ & 15 & $24.5 \pm 2.4$ & 28 & $22.3 \pm 2.2$ & $\mathrm{P}<0.05$ \\
Width $(\mathrm{cm})$ & 15 & $4.0 \pm 0.7$ & 25 & $3.5 \pm 0.7$ & $\mathrm{P}<0.05$ \\
\hline
\end{tabular}


Table 2. Sexual difference in the relative values.

\begin{tabular}{|c|c|c|c|c|c|}
\hline & \multicolumn{2}{|r|}{ Female } & \multicolumn{2}{|r|}{ Male } & \multirow{2}{*}{$\begin{array}{c}\text { Sexual difference } \\
\text { (Mann-Whitney U-test) }\end{array}$} \\
\hline & $n$ & Mean \pm SD & $n$ & Mean \pm SD & \\
\hline Pelvic bone length/Body length (\%) & 15 & $3.1 \pm 0.3$ & 28 & $3.1 \pm 0.2$ & $\mathrm{P}=0.80$ \\
\hline Width/Pelvic bone length (\%) & 15 & $16.5 \pm 2.6$ & 25 & $15.8 \pm 3.4$ & $\mathrm{P}=0.44$ \\
\hline Maximum thickness/Pelvic bone length (\%) & 13 & $6.9 \pm 1.2$ & 23 & $8.6 \pm 1.5$ & $\mathrm{P}<0.05$ \\
\hline $\begin{array}{c}\text { Position of lateral process (\%) } \\
\text { (Cranial tip to lateral process/length) }\end{array}$ & 15 & $62.9 \pm 3.9$ & 25 & $55.9 \pm 4.2$ & $\mathrm{P}<0.05$ \\
\hline
\end{tabular}

On the other hand, the shape of the pelvic bone of modern cetaceans may differ by species, subspecies and others. The pelvic bones of males were larger than that of females in Odontoceti, however, this sexual difference was not detected in Mysticeti. And sexual difference was detected in width of pelvic bones in Bryde's whales [5], while that was not detected in common minke whales in the present study. In addition, taking into consideration the present study with past studies, multiple morphological types exist in males and Twisted type in some males were found only among North Pacific common minke whales. Moreover Heyerdahl (1973) [1] also found among North Atlantic common minke whales that the pelvic bones of female and male were of the Knife-type and Drum stick-type. Knife-type had the shape of a knife that was large in width at lateral process and Drum stick-type was shaped like a drum stick and the width was small. But, in the North Pacific common minke whales, no sexual difference was detected in the width of the pelvic bone in the present study, which is different from Heyerdahl (1973) [1]. And the proportion of pelvic bone length to body length in the present study was larger than that in Heyerdahl (1973) [1] (Mann-Whitney U-test, P < 0.05). Those differences between Heyerdahl (1973) [1] and this study may suggest that the shape of the pelvic bone differs among animals in different regions (Ocean basins) even when the animals are the same species. It is necessary to anatomize soft tissue around pelvic bone, because the shape of pelvic bones is influenced by surrounding tissues.

In the present study, vestigial femurs were found from $98 \%$ of the North pacific common minke whales sampled (42/43 specimens). But Heyerdahl (1973) [1] found vestigial cartilaginous femur from only $3 \%$ of North Atlantic common minke whales ( $1 / 32$ specimens). This suggests that the presence rate of vestigial femur may differ by species or subspecies. However, the vestigial femurs were small in size and frequently composed of cartilage. This may explain why hind limbs may have been overlooked in many previous studies. It is therefore necessary to reexamine the hind limb of modern cetaceans.

\section{Conclusion}

The shape of the pelvic bones and hind limb of modern cetaceans may vary between species and probably by region, or at least by Ocean basin. However, the growth and sexual-related changes, and right and left differences in the shape of pelvic bones have not been clarified, and further studies are needed to characterize the pelvic bone shape by species to elucidate their significance and functional role in modern cetaceans.

\section{Acknowledgements}

We thank Kenji Koizumi of Juntendo University and Haruka Ito of National Research Institute of Fisheries Science, school of medicine for the advice and assistance. Genta Yasunaga and Takeharu Bando of the Institute of Cetacean Research, Hideyoshi Yoshida of the National Research Institute of Far Seas Fisheries, former Chief research staff Shigeo Tabata, Yoshiichi Shimomichi and the crew of the Association for Community-Based Whaling are acknowledged for assisting in sampling. We also express thanks to Kozue Ishida, Satoko Inoue and members of the Laboratory of Cetacean Biology, Tokyo University of Marine Science and Technology.

\section{References}

[1] Heyerdahl Jr., T. (1973) Sexual Dimorphism and Age Criteria in the Pelvic Bones of the Minke Whale, Balaenoptera acutorostrata Lacepede. Norwegian Journal of Zoology, 21, 39-43.

[2] Bejder, L. and Hall, B.K. (2002) Limbs in Whales and Limblessness in Other Vertebrates: Mechanisms of Evolutionary and Developmental Transformation and Loss. Evolution \& Development, 4, 445-458. 
http://dx.doi.org/10.1046/j.1525-142X.2002.02033.x

[3] Hosokawa, H. (1951) On the Pelvic Cartilages of the Balaenoptera-Foetuses, with Remarks on the Specifical and Sexual Difference. Scientific Reports of the Whales Research Institute, 5, 5-15.

[4] Nakamura, G. and Kato, H. (2014) Osteological Characteristics of Gray Whales Eschrichtius robustus Collected from the Coast of Japan (1990-2005) and Possible Population Mixing with Eastern Gray Whales in the Western North Pacific. Mammalian Science, 54, 73-86.

[5] Miyakawa, N. and Kato, H. (2015) Morphology of Innominate Bones (Pelvic Bones) of Bryde's Whales Balaenoptera edeni. Mammalian Science, 55, 1-10.

[6] Tajima, Y., Hayashi, Y. and Yamada, T.K. (2004) Comparative Anatomical Study on the Relationships between the Vestigial Pelvic Bones and the Surrounding Structures of Finless Porpoises (Neophocaena phocaenoides). Journal of Veterinary Medical Science, 66, 761-766. http://dx.doi.org/10.1292/jvms.66.761

[7] Perrin, W.F. (1975) Variation of Spotted and Spinner Porpoise (Genus Stenella) in the Eastern Pacific Hawaii. Bulletin of the Scripps Institution of Oceanography, 21, 1-206.

[8] Ito, H. and Miyazaki, N. (1990) Skeletal Development of the Striped Dolphin (Stenella coeruleoalba) in Japanese Waters. Journal of Mammalogical Siciety of Japan, 14, 79-96.

[9] Yoshida, H., Shirakihara, M., Takemura, A. and Shirakihara, K. (1994) Development, Sexual Dimorphism, and Individual Variation in the Skeleton of the Finless Porpoise, Neophocaena phocaenoides, in the Coastal Waters of Western Kyusyu, Japan. Marine Mammal Science, 10, 266-282. http://dx.doi.org/10.1111/j.1748-7692.1994.tb00482.x

[10] Galatius, A. (2005) Sexually Dimorphic Proportions of the Harbor Porpoise (Phocoena phocoena) Skeleton. Journal of Anatomy, 206,141-154. http://dx.doi.org/10.1111/j.1469-7580.2005.00381.x

[11] Iris, C., Natalia, A.D., Lida, E.P., Federico, P., Guillermo, H.C. and Natalie, P.G. (2015) Sexual Dimorphism and Morphometric Relationship in Pelvic Bones of Commerson's Dolphins (Cephalorhynchus c. commersonii) from Tierra del Fuego, Argentina. Marine Mammal Science, 31, 734-747. http://dx.doi.org/10.1111/mms.12172

[12] Lönnberg, E. (1910) The Pelvic Bones of Some Cetacea. Arkiv För Zoologi, 7, 1-15.

[13] Arvy, L. (1979) The Abdominal Bones of Cetaceans. In: Pilleri, G., Ed., Investigations on Cetacea, Vol. 10, Brain Anatomy Institute, Berne, 215-227.

[14] Omura, H. (1980) Morphological Study of Pelvic Bones of the Minke Whale from the Antarctic. Scientific Reports of the Whales Research Institute, 32, 25-37. 